\title{
Extraordinary Persistence of Foehn Observed in the Hokuriku District of Japan in the 1999 Summer
}

\author{
Hiroyuki INABA, Ryuichi KAWAMURA \\ Department of Earth Sciences, Toyama University, Toyama, Japan \\ Takahiro KAYAHARA \\ National Research Institute for Earth Science and Disaster Prevention, Tsukuba, Ibaraki, Japan \\ and \\ Hiroaki UEDA ${ }^{1}$ \\ Meteorological Research Institute, Tsukuba, Ibaraki, Japan
}

(Manuscript received 12 November 2001, in revised form 21 April 2002)

\begin{abstract}
An unusually prolonged foehn was observed at Toyama in the Hokuriku district, located on the coast of the Sea of Japan of central Japan, from 30 July to 3 August 1999. A 5-day foehn is extraordinarily persistent and was not observed during the 24-year period 1975-1998, which makes the 1999 summer quite exceptional. While an anticyclone east of Japan is intensified over the 5-day period, a combination of the anticyclone with a rapidly developing cyclone over southeastern Siberia and a typhoon migrating northward into the East China Sea induces a definite intensification of southerly geostrophic winds over central Japan, a favorable condition for the occurrence of unusually prolonged foehn.

Observational and model results show that on a monthly mean basis, a noticeable east-west pressure gradient around Japan is present due to the prominence of the Pacific and Japan (PJ) teleconnection pattern in response to tropical convective heating, resulting in reinforcing southerly geostrophic winds across central Japan. Once large-scale circulation anomalies are initiated and sustained as a result of such an extratropical response, the development and movement of adjacent synoptic-scale disturbances are largely regulated by those anomalies. A combined effect of the excitation of the PJ pattern and associated synoptic-scale disturbances is crucial for the extraordinary persistence of foehn along the coast of the Sea of Japan. The PJ pattern that appeared in July 1999 has an unusual geographical location and configuration because enhanced cumulus convection over the warm pool region of the western North Pacific is significantly displaced about $20^{\circ}$ westward and $2-3^{\circ}$ northward, compared to the typical hot summer that Japan experiences. This displacement is presumably attributed to a similar shift of distinctive warm SST anomalies over the warm pool region.
\end{abstract}

Corresponding author: Ryuichi Kawamura, Department of Earth Sciences, Toyama University, 3190 Gofuku, Toyama 930-8555, Japan.

E-mail: kawamura@sci.toyama-u.ac.jp

1 Present affiliation: Institute of Geoscience, University of Tsukuba, Tsukuba, Ibaraki 305-8571, Japan.

E-mail: hueda@kankyo.envr.tsukuba.ac.jp

(C) 2002, Meteorological Society of Japan

\section{Introduction}

The foehn phenomenon, one of the intriguing local winds appearing frequently in the mountain region as well as the bora, has been investigated by a number of meteorologists and climatologists around the world. According to 


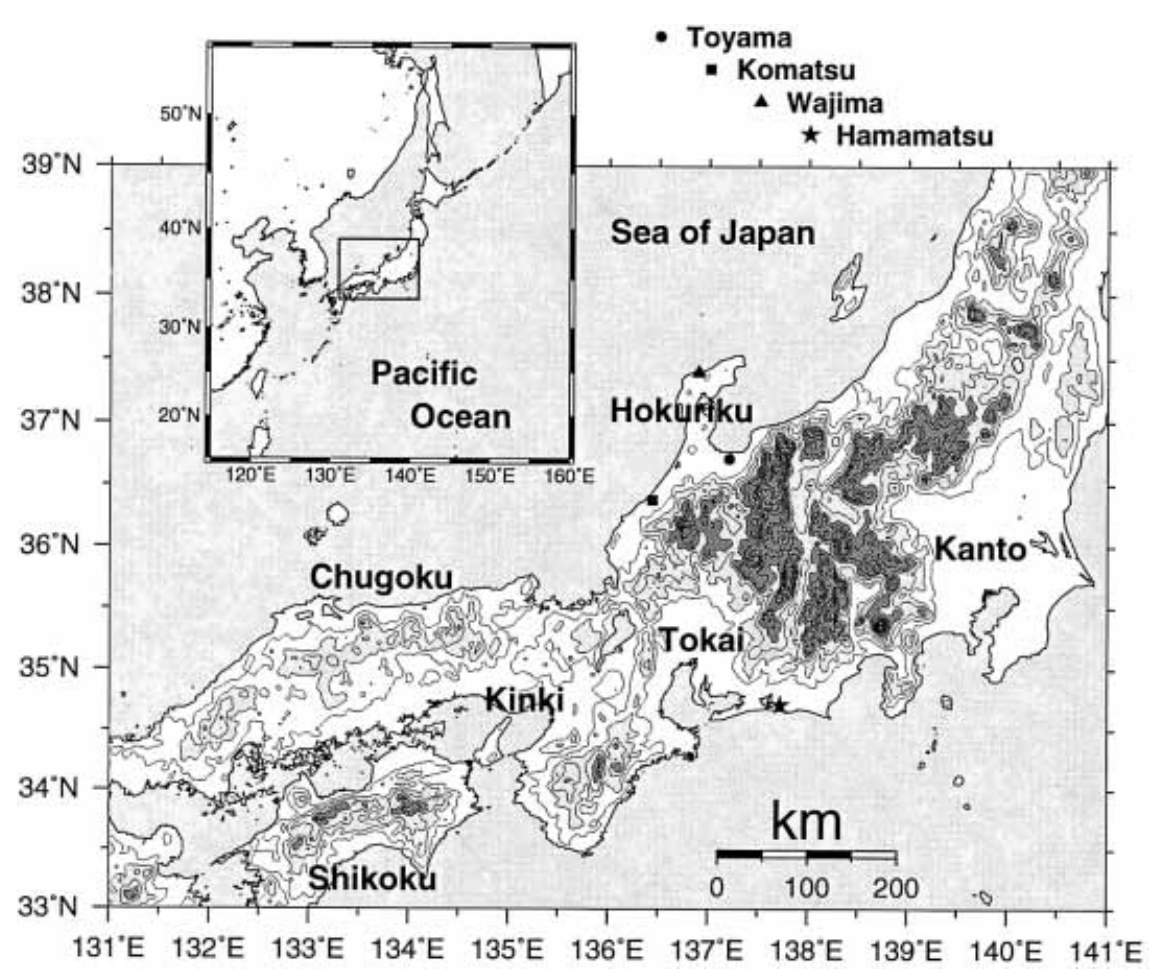

Fig. 1. Geographical map of central Japan analyzed in this study.

Yoshino (1976), who reviewed local winds, especially bora, the definitions of the foehn and bora are made simply or practically as follows: the foehn is a downward wind on the leeward side of a mountain range. When it blows, the air temperature on the leeward slope rises. The bora also is a downward wind on the leeward side of a mountain range, but when it commences, the air temperature on the leeward slope falls. Such local winds depend strongly on the configuration of the land, the pressure field at the level of the mountain peaks, and the atmospheric stability (e.g., Ikawa and Nagasawa 1989; Saito and Ikawa 1991; Saito 1993). The occurrence of extremely strong foehns in midsummer brings about the outstanding increase in daily maximum temperature and the decrease in daily minimum humidity, eventually damaging a variety of crops including grains, vegetables, and fruits. A combined effect of the foehn occurrence and the heat island phenomenon in urban areas also creates discomfort and increases daily electricity consumption due to the continuous use of air conditioners. Daily life and economic activities thus are vulnerable to the occurrence of foehn that causes extreme weather.

Since the Toyama Plain in the Hokuriku district of Japan is surrounded by the Hida Mountains and other high mountains to the south, as shown in Fig. 1, it tends to frequently undergo salient foehns on the leeward slope, due to strong pressure gradient across central Japan when well-developed extratropical or tropical cyclones pass through the Sea of Japan (e.g., Arakawa 1988). An extremely strong foehn has been observed at Toyama from the end of July to the beginning of August 1999. Foehns prevail only a couple of days in most cases, but this exceptional foehn predominated longer than at least 3 days and the daily maximum temperature at Toyama reached $38.8^{\circ} \mathrm{C}$ on July 31. Was such persistence of foehn abnormal? If so, what caused the persistent foehn? Was the dominance of foehn confined only to the Toyama Plain? Was the frequent occurrence of foehn significantly associated with a severe hot summer in Japan?

Our main purposes of this study are (1) to verify whether or not the prolonged foehn ob- 
served at Toyama in the midsummer of 1999 is an exceptional case in recent years and (2) to identify what dynamic processes make the foehn persist longer than at least 3 days, using various observational data and an atmospheric general circulation model (AGCM). Section 2 describes data used and the analysis procedure. In Section 3 we briefly document interannual evolution of the summertime occurrence frequency of foehn days observed at Toyama in recent years. Section 4 shows regional features of surface air temperature, wind, and precipitation fields when the foehn prevails in the Hokuriku district. In Section 5 we examine what synoptic-scale disturbances in the vicinity of Japan are crucially responsible for the persistent foehn. Section 6 examines how the anomalous circulations, which provide a favorable condition for the persistence, are induced in the midsummer of 1999 on the basis of model results. Discussion and concluding remarks are found in Section 7.

\section{Data used and analysis procedure}

\subsection{Extraction of extreme foehns}

Based on the Japan Meteorological Agency (JMA) observational station data during the period 1975-1999, we defined a pronounced foehn, seen at Toyama city in midsummer (July-August) on a daily basis, using the following four criteria:

i) daily maximum temperature is greater than $35^{\circ} \mathrm{C}$,

ii) daily minimum relative humidity is less than $45 \%$,

iii) daily mean wind speed is greater than $3 \mathrm{~m} \mathrm{~s}^{-1}$, and

iv) daily most frequent wind direction is SSW, $\mathrm{S}, \mathrm{SSE}$ or SE.

The above second and third criterions are quite reasonable because the foehn is characterized by unusually dry and strong winds on the leeward side of the mountain range. Since it is anticipated that the foehn contributes frequently to the occurrence of unusual hot weather exceeding $35^{\circ} \mathrm{C}$, the first criterion is also introduced. We further applied the fourth criterion to the definition of foehn because the Toyama Plain is surrounded by high mountains to the south, and strong southerly winds on the leeward side are an important indication of foehn in this region. According to the above classification, we identified the number of foehn day occurrences for each midsummer and obtained interannual variation of the summertime occurrence frequency of foehn days at Toyama from 1975 through 1999. Note that we did not consider any foehns that occurred before 1975, owing to the lack of daily most frequent wind direction data.

\subsection{Observational data}

To clarify regional features of foehns in the 1999 summer, we use surface air temperature, wind velocity and direction, and precipitation data derived from 778 AMeDAS (Automated Meteorological Data Acquisition System) stations of JMA on mainland Japan, and sonde data from two selected stations: Wajima station, the nearest to Toyama, and Hamamatsu station on the coast of the Pacific Ocean. As the next step, to examine anomalous circulations in the vicinity of Japan relevant to the extraordinary persistence of foehn, we use the GANAL (JMA global objective analysis) data with a spatial resolution of $1.25^{\circ}$ in longitude and latitude and 3-hourly infrared equivalent blackbody temperature $\left(T_{B B}\right)$ with a spatial resolution of $1^{\circ} \times 1^{\circ}$ derived from the Japanese geostationary meteorological satellite, providing an appropriate measure of anomalous convection in lower latitudes. Also used for the corresponding period are 10-day mean sea surface temperature (SST) data of JMA, with a resolution of $1^{\circ}$ in longitude and latitude over the western North Pacific from $100^{\circ} \mathrm{E}$ to $180^{\circ}$ between the equator and $60^{\circ} \mathrm{N}$. We further use the National Centers for Environmental Prediction/National Center for Atmospheric Research (NCEP/NCAR) global atmospheric reanalysis dataset; monthly outgoing longwave radiation (OLR) data with a spatial resolution of $2.5^{\circ} \times 2.5^{\circ}$ observed from NOAA satellites; and the Global Ice and SST (GISST) dataset (Parker et al. 1995) for a comparison between the 1999 summer and a typical hot summer.

\subsection{Model simulation}

For this study we used a T42 AGCM version of JMA (JMA-GSM89) global model with 21 levels (JMA 1993; Sugi et al. 1990). The horizontal resolution is equivalent to approximately $2.8^{\circ}$ longitude by $2.8^{\circ}$ latitude. The parameterization of deep convection in the model 
employs a modified Kuo scheme. In radiation processes, longwave cooling and solar heating with interactive cloud are taken into account. The land surface process utilizes a simple biosphere model. The surface exchanges employ the Louis scheme for surface moisture, heat, and momentum fluxes, and a Möller and Yamada level-2 closure model for vertical diffusion. Kawamura et al. (1998) have already conducted an ensemble of three independent 40-year integrations from 1955 to 1994 , employing prescribed global SSTs. These three independent integrations are extended to August 1999 using the SST data stated above to pay special attention to the summer of 1999. The three parallel simulations are subjected to the same SST boundary conditions. The ensemble mean process is expected to be very useful for inspecting the influence of anomalous SST forcing from the tropics in extratropical circulation anomalies in the vicinity of Japan because the internal variability of the extratropical model atmosphere is considerably reduced.

\section{Occurrence frequency of foehns}

Based on the definition of foehn stated earlier, we extracted significant foehns observed at Toyama during the midsummer season (JulyAugust). Figure 2 shows the number of foehn

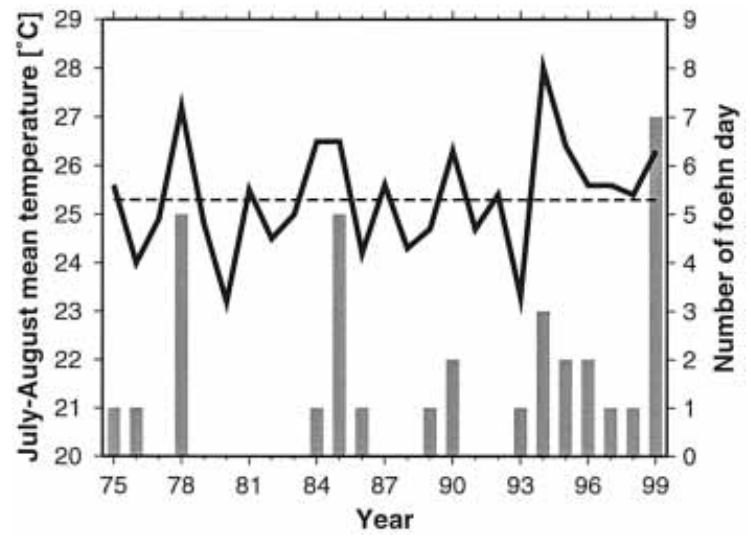

Fig. 2. Time series of the number of foehn day occurrences at Toyama in midsummer (July-August) during the 25-year period 1975-1999 (bar). Also shown are the interannual variation of the July-August mean surface air temperature at the same station (solid line) and its 25-year average (dashed line). day occurrences at Toyama for each midsummer from 1975 to 1999 (bar), together with the time sequence of the July-August mean surface air temperature (solid line). Foehn occurs 7 days in the summer 1999, which is the largest number of the foehn days in the analyzed period. A sequence of 5 days out of the 7 days occurs from July 30 to August 3, 1999, as shown later. The second largest number of the occurrences is observed in the summers of 1978 and 1985. The number of summers when no marked foehns prevailed is 10 . We see no definite foehns during the years from 1979 to 1983. The relationship between the foehn's occurrence frequency and the mean temperature is not necessarily significant. Actually, although the 1994 summer is warmest summer in recent years, and the mean temperature is $28.0^{\circ} \mathrm{C}$, the occurrence of foehn is only 3 days, while the 1999 summer when foehns appeared most frequently is not an extremely hot summer. What we would like to stress here is that the 1999 summer is an exceptional case in the last two decades in terms of the occurrence frequency of foehns.

Figure 3 shows the time evolutions of daily maximum temperature, daily minimum rela-

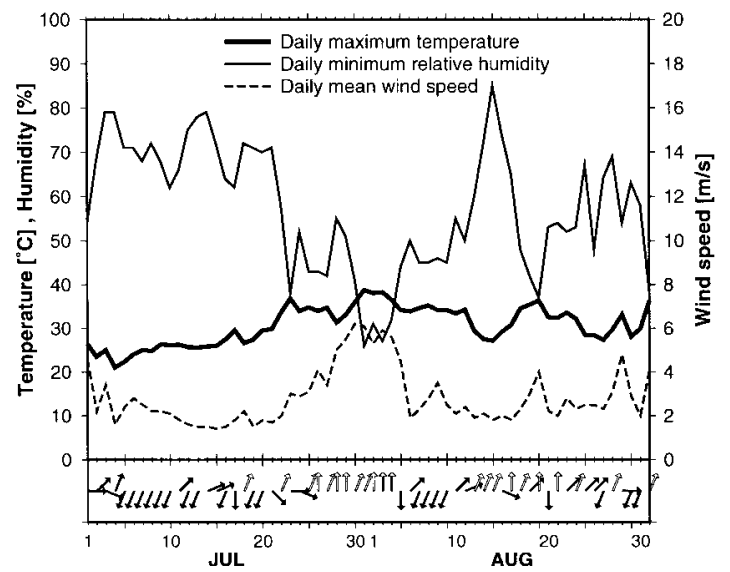

Fig. 3. Time series of daily maximum temperature (thick line), daily minimum relative humidity (thin line), daily mean wind speed (dashed line), and daily most frequent wind direction (arrow) at Toyama from July to August 1999. Upward arrow denotes southerly wind. Opened arrow represents the wind direction that satisfies the fourth criterion (see text). 
tive humidity, daily mean wind speed, and daily most frequent wind direction at Toyama from July to August of 1999. The occurrence of severe hot weather exceeding $35^{\circ} \mathrm{C}$ is 10 days over the whole period. Seven days out of the 10 days are classified as foehn days (July 30August 3, August 19 and 31). The daily minimum relative humidity is remarkably low, less than $30 \%$, from late July to early August, especially on July 31 and August 2. The daily mean wind speed shows high values for almost the same period, reaching about $6 \mathrm{~m} \mathrm{~s}^{-1}$ from July 30 to August 3. Thus, extreme values for these three variables are concentrated mostly in the period from the end of July to the beginning of August. Moreover, the most frequent daily wind direction is SSW or S during this period. It is understood, as a consequence, that a sequence of 5 foehn days (July 30-August 3) made the 1999 summer quite exceptional. Such extraordinary persistence of foehn with 5 days is not observed during the 24-year period 1975-1998.

\section{Regional features}

This section focuses on the regional features of surface air temperature, wind speed and di- rection and precipitation fields derived from AMeDAS stations over central Japan during the period when the 5 sequential foehn days is observed at Toyama. As is well known, local wind patterns over central Japan are generally very complicated, due to the prominence of various local winds such as land and sea breeze. To specifically highlight the regional features only relevant to the foehn, we computed daily mean surface air temperature and daily mean surface wind speed and direction, resulting in the reduction of their diurnal cycles. Also considered are daily total precipitation distributions to infer what type of foehn dominates. These regional patterns show a significant difference between the early and later periods of the foehn sequence of 5 days. Thus, we demonstrate the regional features of July 31 and August 2 as a typical case for each period.

Figure 4 shows the distributions of daily mean surface air temperature and wind speed and direction in central Japan on July 31 . The most notable feature in this figure is that very hot areas exceeding $28^{\circ} \mathrm{C}$ extend entirely along the mainland coast of the Sea of Japan, which is quite different from the Pacific Ocean side. The temperature difference between the two

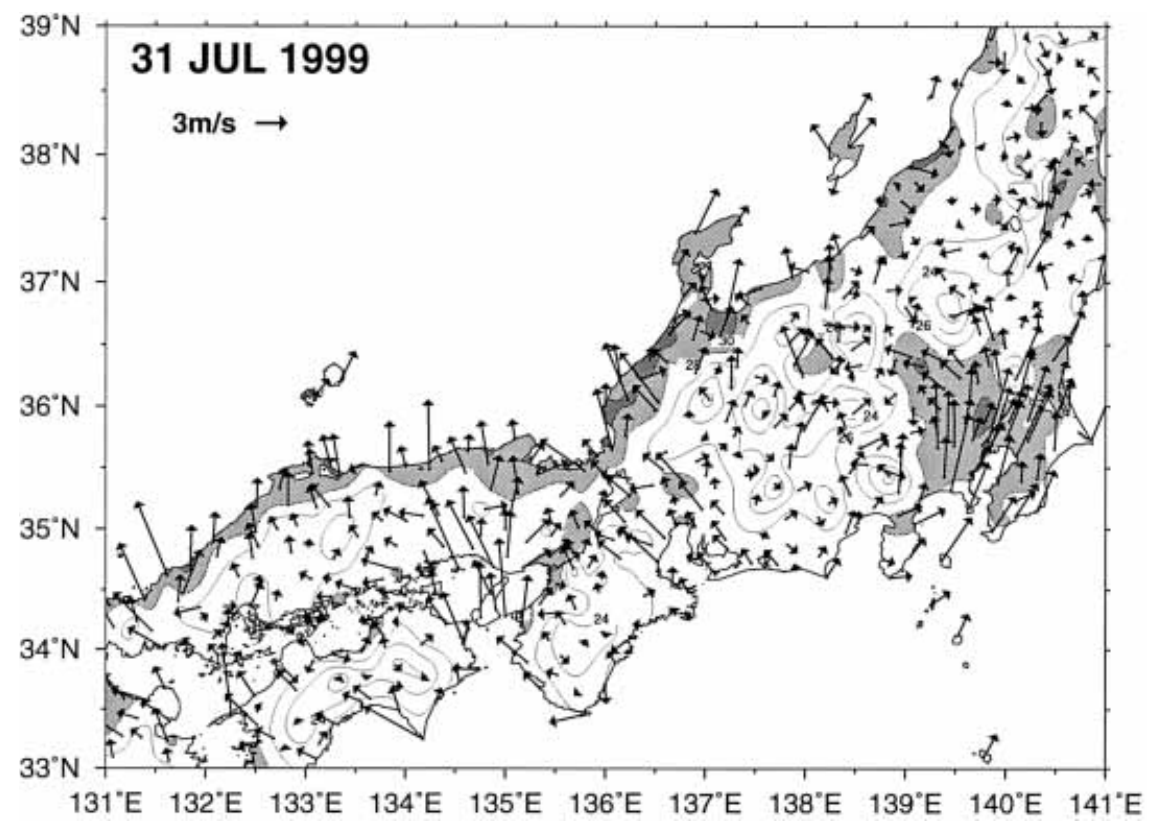

Fig. 4. Spatial distribution of daily mean surface air temperature and wind speed and direction in central Japan on 31 July 1999. Contour interval is $2^{\circ} \mathrm{C}$, and shading denotes regions greater than $28^{\circ} \mathrm{C}$. Reference arrow is $3 \mathrm{~m} \mathrm{~s}^{-1}$. 


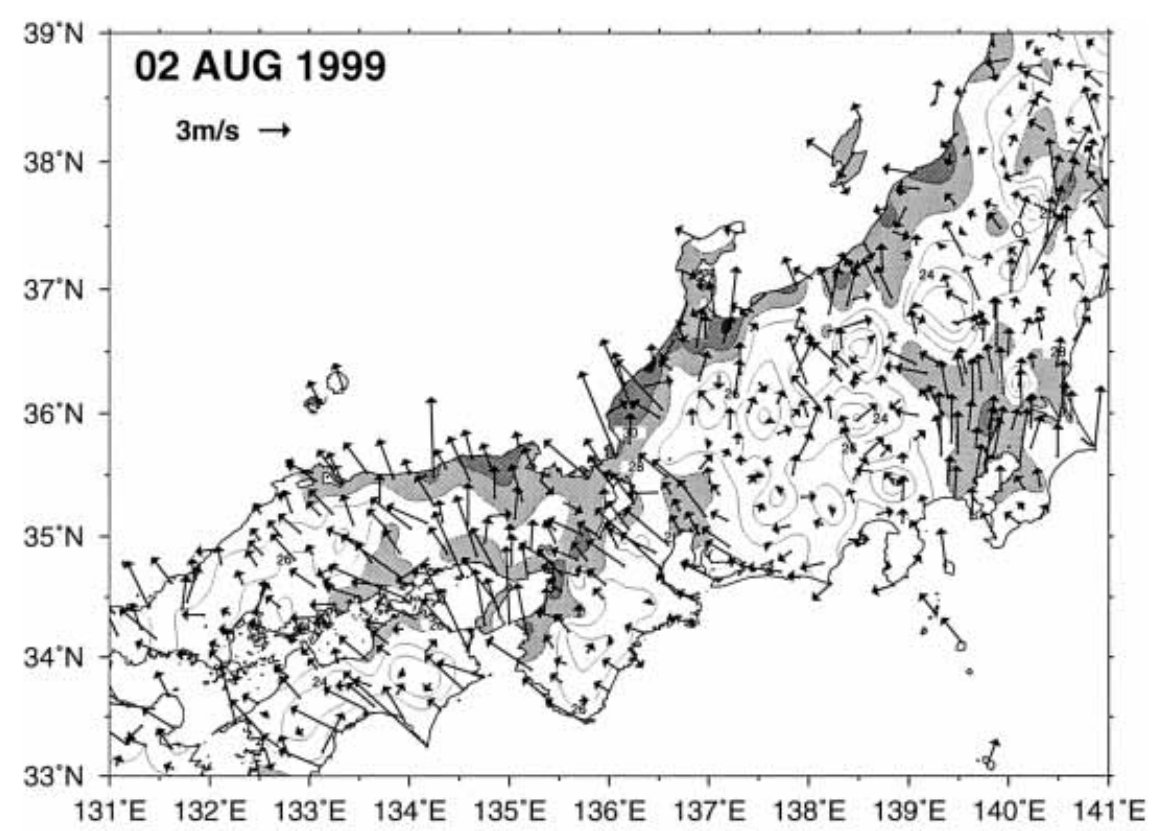

Fig. 5. As in Fig. 4 but for 2 August 1999.

sides is about 3 to $4^{\circ} \mathrm{C}$. Several cities (e.g., Toyama and Komatsu) in the Hokuriku district experience severe hot weather, with greater than $30^{\circ} \mathrm{C}$ daily mean temperature. It turns out that these hot areas along the coast of the Sea of Japan are accompanied by significantly strong southerly winds over $3 \mathrm{~m} \mathrm{~s}^{-1}$. The Chugoku district is also one of the regions where the foehn tends to appear frequently on the coast of the Sea of Japan when strong southerlies prevail across comparatively high mountains. These features suggest that the foehn predominates not only at the Toyama Plain, but also in the Hokuriku and Chugoku districts. Very interestingly, the high temperatures also cover the Kanto Plain, especially the Tokyo area, over $28^{\circ} \mathrm{C}$, with strong south to southwesterly winds. Although we understand that the heat island phenomenon due to largescale urbanization contributes to such high temperatures, this effect is beyond the scope of this study.

Figure 5 shows the distributions of daily mean surface air temperature and wind speed and direction in central Japan on August 2. In a similar fashion, very hot areas extend over a wide region on the coast of the Sea of Japan. If we look at the Hokuriku district, Toyama and
Komatsu are observed to further heat up to $32^{\circ} \mathrm{C}$. A noticeable difference between July 31 and August 2 is the local wind pattern in the western half of central Japan in terms of wind direction. An easterly wind component is more evident on August 2 than on July 31, although southerly winds predominate on both days. The daily mean wind speed exceeding $5 \mathrm{~m} \mathrm{~s}^{-1}$ is also observed in a number of stations on $\mathrm{Au}$ gust 2 . These changes suggest that the behavior of synoptic-scale disturbances in the vicinity of Japan significantly differs for each period.

Another remarkable difference between July 31 and August 2 is the daily total precipitation distribution on the Pacific Ocean side of central and western Japan. Figures 6 and 7 display the daily total precipitation pattern on July 31 and August 2, respectively. On July 31, weak precipitation, with values of about $10-20 \mathrm{~mm}$, is observed in the Shikoku and Kinki districts, but there is no significant precipitation around the Hida Mountains, which may imply that the foehn prevailing in the Hokuriku district is identified with a dynamically-induced foehn accompanied by no precipitation on the windward side of a mountain range (e.g., Scorer and Klieforth 1959; Ikawa and Nagasawa 1989). In contrast, on August 2 heavy precipitation 


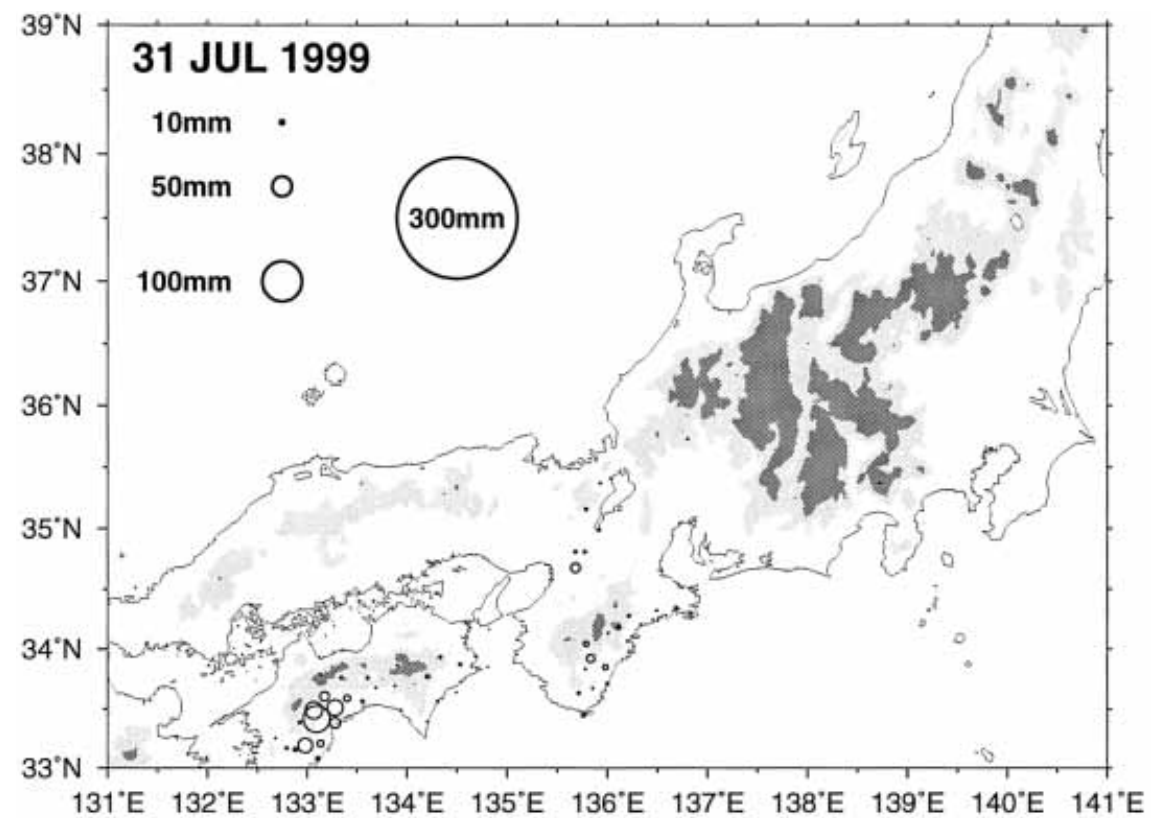

Fig. 6. Spatial distribution of daily total precipitation in central Japan on 31 July 1999. Large, medium, and small circles denote precipitation with values of $100 \mathrm{~mm}, 50 \mathrm{~mm}$ and $10 \mathrm{~mm}$, respectively.

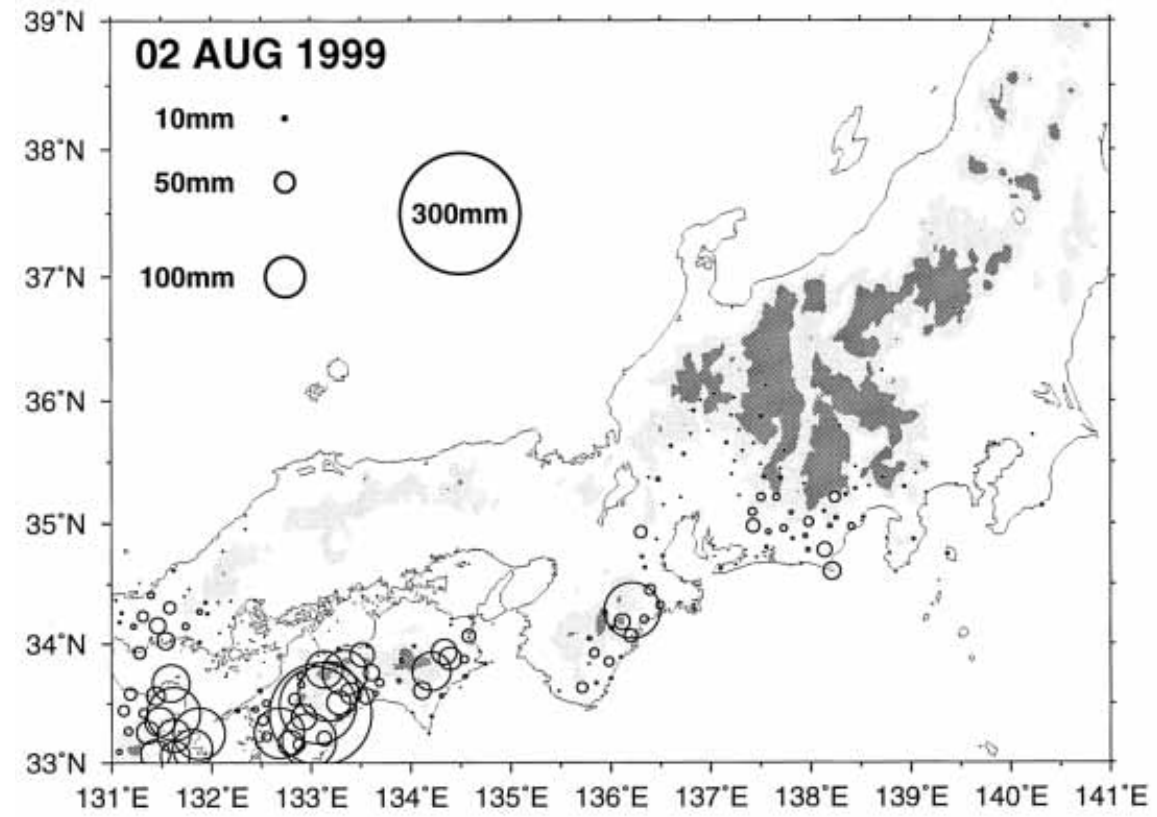

Fig. 7. As in Fig. 6 but for 2 August 1999. 


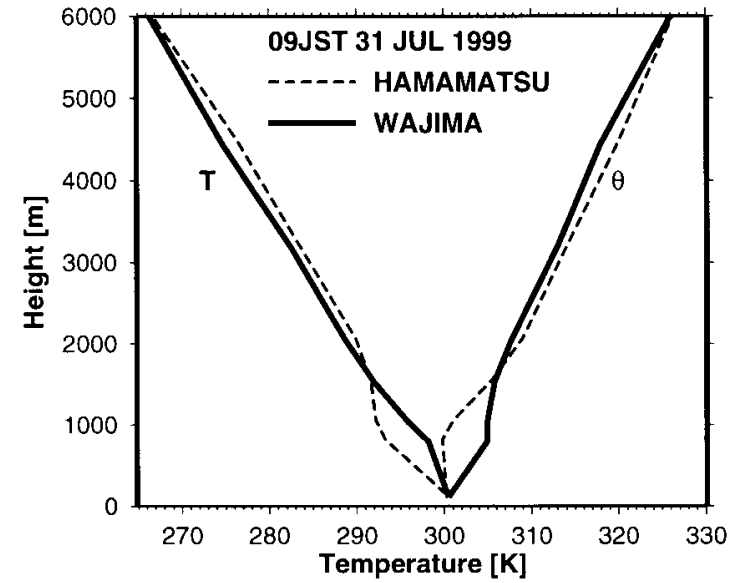

Fig. 8. Vertical profiles of air temperature and potential temperature from near-surface to $6000 \mathrm{~m}$ in height at Wajima station (solid line) and Hamamatsu station (dashed line) at 09 JST 31 July 1999.

exceeding $100 \mathrm{~mm}$ occurs, especially in the Shikoku and part of Kyusyu districts, and we also see somewhat weak precipitation less than $50 \mathrm{~mm}$ on the Pacific Ocean side of Tokai district to the south of the Hida Mountains. As shown in Figs. 4 and 5, hot weather conditions in the Hokuriku district on a daily mean basis are more severe on August 2 than on July 31. Furthermore, hot areas over $28^{\circ} \mathrm{C}$ expand into the Kinki district. It appears that the so-called classical foehn, which is a thermodynamical foehn accompanied by precipitation on the windward side of a mountain range, contributes to further reinforcement and extension of severe hot conditions in the Hokuriku and Kinki districts.

Figure 8 shows the vertical profiles of air temperature and potential temperature at 09 JST 31 July observed at Wajima and Hamamatsu sonde stations, which were selected as reference stations on the leeward and windward sides of high mountain ranges in central Japan, respectively. Both stations exhibit a very similar vertical structure in the layer above about $2000 \mathrm{~m}$ in height, but a quite different structure can be found in the boundary layer, especially below $1500 \mathrm{~m}$ in height. A convective mixed layer is seen below about $800 \mathrm{~m}$ in height at Hamamatsu station, but it is capped by a very stable layer between $800 \mathrm{~m}$ and $1500 \mathrm{~m}$. At Wajima station, in contrast, an extremely stable layer is established below around $800 \mathrm{~m}$ in height. Although there exists a remarkable difference in the stratification below $1500 \mathrm{~m}$ between the two stations, it is uncertain whether the foehn observed at Toyama extends up to Wajima station in the Noto Peninsula, about $100 \mathrm{~km}$ from the Hida Mountains. Unfortunately, we cannot make sure which type of foehn, a dynamical or a thermodynamical foehn, was more dominant during the 5 days from July 30 to August 3 due to a shortage of sonde station data.

\section{Synoptic-scale features in the vicinity of Japan}

In this section we focus on synoptic-scale disturbances in the vicinity of Japan associated with the extraordinary persistence of foehn. Figures 9 and 10 illustrate the spatial patterns of twice daily $850-\mathrm{hPa}$ height and wind vector and $T_{B B}$ during the periods of July $30-31$ and August 1-2, respectively. Taking a look at the early period (Fig. 9), an intensified anticyclone, which is part of the North Pacific High, is observed to the east of Japan, whereas a rapidly developing cyclone with a stationary component is located over southeastern Siberia of the Asian continent. We also have a cloud band across the Korean Peninsula at 21 JST 31 July, corresponding to a frontal system of the extratropical cyclone. It is obvious that the pressure gradient between the two systems across Japan becomes pronounced, which implies the prominence of geostrophic wind just over Japan. Over central Japan the geostrophic wind has an evident southerly component, eventually facilitating the occurrence of foehn on the northern slope of a high mountain range, especially in the Hokuriku district. Likewise, a typhoon develops and moves northwestward along the southwestern periphery of the enhanced anticyclone system.

At the later period (Fig. 10) the anticyclone east of Japan is still dominant, but the extratropical cyclone over southeastern Siberia begins to move eastward into the Sea of Okhotsk and disappears rapidly, nearly concurrent with the northward extension of the North Pacific High. The typhoon, on the other hand, continues to intensify and move northwestward 
(a) 09JST 30 JUL 1999

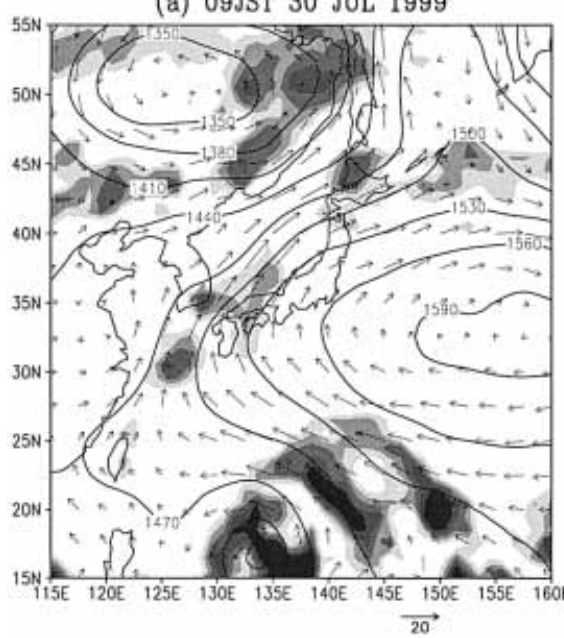

(c) 09JST 31 JUL 1999

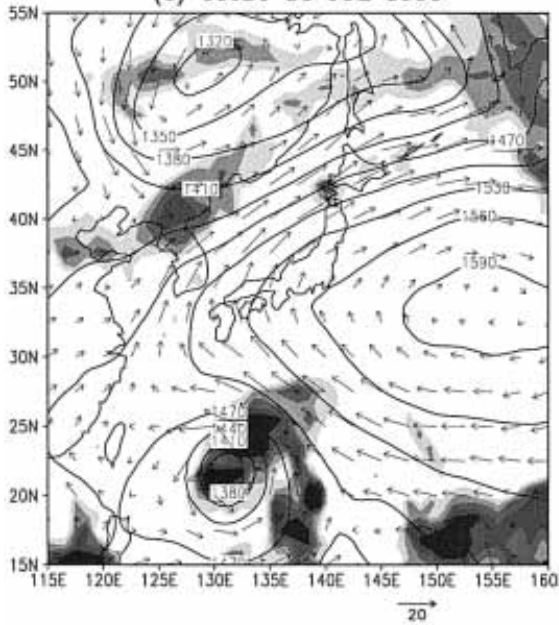

(b) 21JST 30 JUL 1999

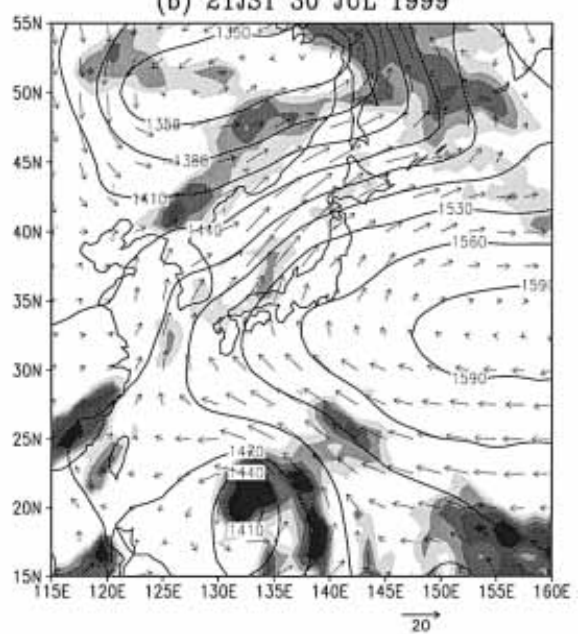

(d) 21JST 31 JUL 1999

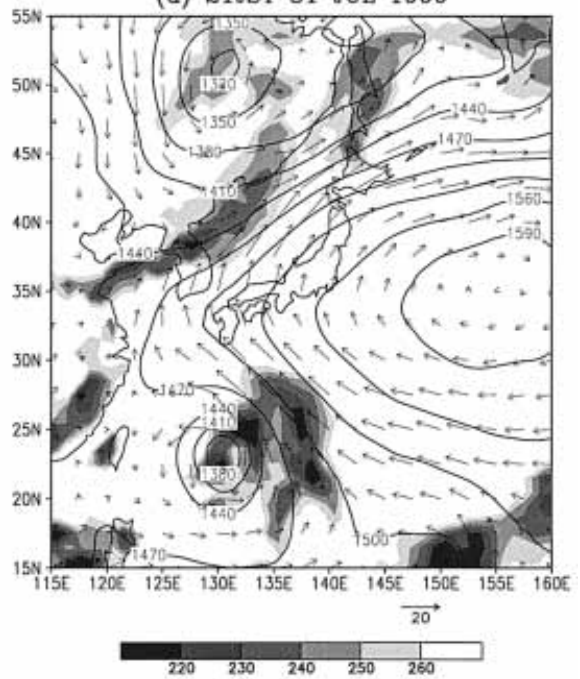

Fig. 9. Spatial pattern of twice daily $850-\mathrm{hPa}$ height and wind vector and $T_{B B}$ from 09 JST 30 July to $21 \mathrm{JST} 31$ July 1999 . Contour interval is $30 \mathrm{~m}$, and reference arrow is $20 \mathrm{~m} \mathrm{~s}^{-1}$.

into the East China Sea. The cloud band structure across the Korean Peninsula becomes less clear with the weakening of the low pressure system over the continent by 21 JST 1 August, but on August 2 it is largely modified by the increased moisture supply from the approaching typhoon. It is inferred that the enhanced northward moisture transport at the lowlevels contributes substantially to the occurrence of heavy precipitation events over western Japan, especially Shikoku and Kyusyu districts, as shown in Fig. 7. A combination of the two major systems, i.e., the typhoon and anticyclone systems, induces a new strong east-west pressure gradient around Japan and enhances southerly geostrophic winds across the high mountain range.

We would like to emphasize here that the southerly geostrophic winds over central Japan are definitely intensified during both periods, due to the presence of strong pressure gradient, although synoptic-scale disturbances that induce such a pressure gradient differ appreciably for each period. This results in the extraordinary persistence of the foehn from July 30 to August 3. A common feature in both periods is the enhancement of the anticyclone east of Japan. The strengthened anticyclonic circu- 
(e) 09JST 01 AUG 1999

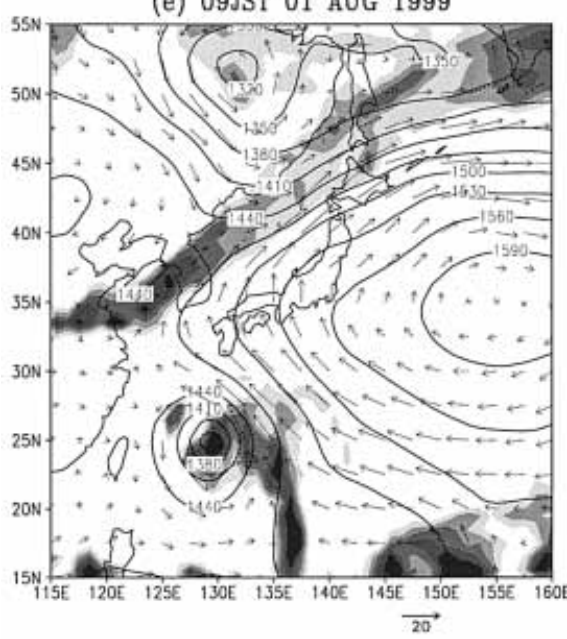

(g) 09JST 02 AUG 1999

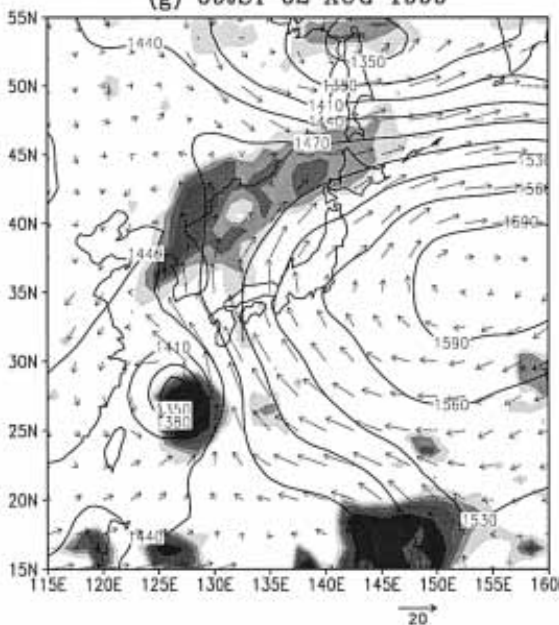

(f) 21JST 01 AUG 1999

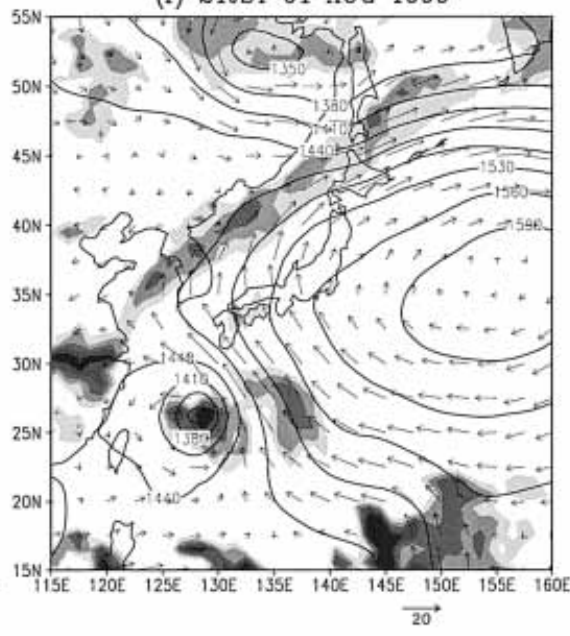

(h) 21JST 02 AUG 1999

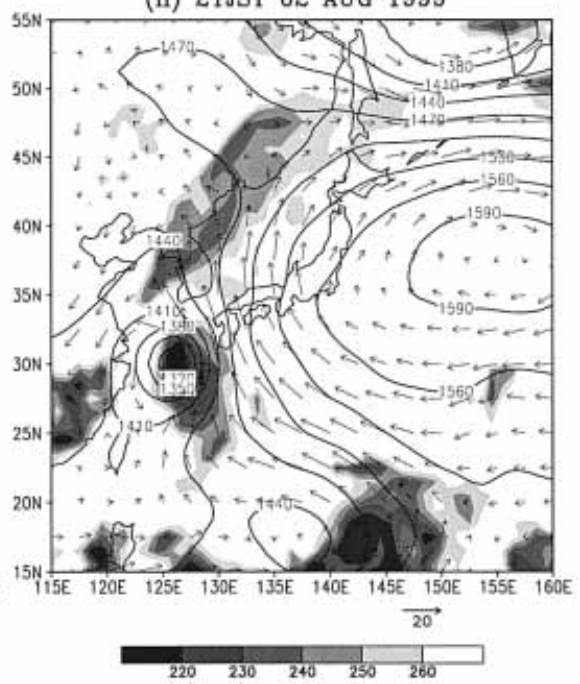

Fig. 10. As in Fig. 9 but for from 09 JST 1 August to 21 JST 2 August 1999.

lation blocks the penetration of the typhoon into the vicinity of Japan, and hence the typhoon is forced to migrate northward along the western periphery of the anticyclone. As a result, a distinctive pressure gradient is induced at the later period. The intensified anticyclone, moreover, might activate the stationary nature of the low-pressure system over southeastern Siberia at the early period, by preventing eastward movement of the cyclonic disturbance. Even not so, the enhanced anticyclonic circulation provides a favorable condition for the formation of the marked pressure gradient across Japan between its circulation and a developing cyclonic disturbance over the continent. It should be noted, therefore, that the intensified anticyclone east of Japan is responsible for the occurrence of unusually prolonged foehn, in the sense that the system significantly influences the behavior of adjacent synoptic-scale disturbances.

\section{Large-scale circulation anomalies}

In the previous section we showed how synoptic-sale conditions in the vicinity of Japan facilitate the extraordinary persistence of foehn observed in the Hokuriku district. An important question that needs to be addressed is why such specific synoptic-scale conditions are induced and maintained. In particular, we should 


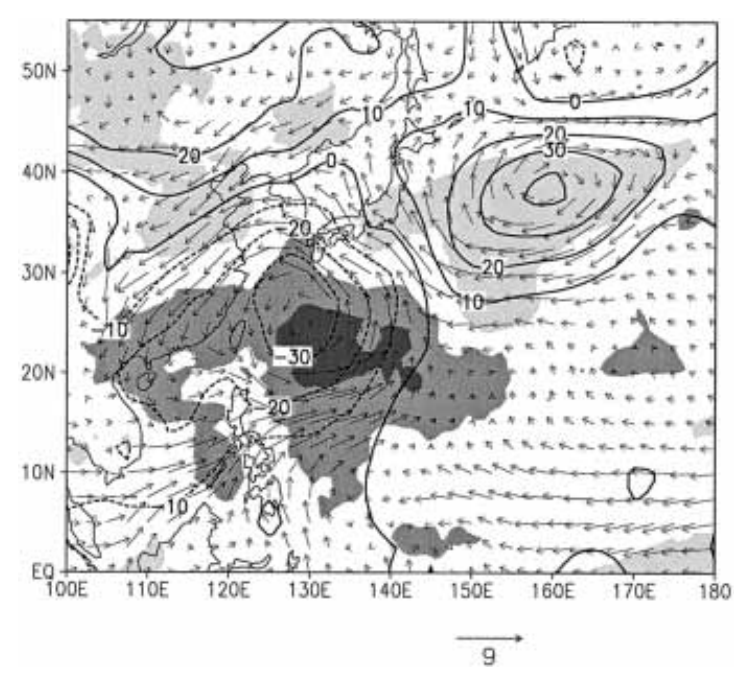

Fig. 11. Observed monthly mean 850$\mathrm{hPa}$ height and wind vector and $T_{B B}$ anomaly patterns for July 1999. Anomalies are relative to the 1980 to 1999 average. Contour interval is $10 \mathrm{~m}$, and negative height values are denoted by dashed lines. Heavy and light shadings denote significant negative and positive $T_{B B}$ anomalies, respectively. Reference arrow is $9 \mathrm{~m} \mathrm{~s}^{-1}$.

make clear a possible cause of the intensification of the anticylonic circulation east of Japan over the period. Of much interest is that its intensification commences several weeks before the occurrence of the exceptionally prolonged foehn (figure not shown).

\subsection{Observations}

Figure 11 shows the observed monthly mean $850-\mathrm{hPa}$ height and wind vector and $T_{B B}$ anomaly patterns for July 1999. Anomalies are relative to the 1980 to 1999 average. A notable feature is that an outstanding anticyclonic circulation anomaly is organized to the east of Japan, while an anomalous cyclonic circulation dominates over an ocean area between the Philippines and Japan. The pronounced anticyclonic and cyclonic circulation anomalies are accompanied by positive and negative $T_{B B}$ anomalies, respectively. The center of the anomalous cyclonic circulation, which is essentially baroclinic in the vertical, is located northwest of the center of intense convection. We can interpret the cyclonic circulation anom- aly in the subtropics as Matsuno-Gill type response (Matsuno 1966; Gill 1980) of the lower troposphere to enhanced convective heating away from the equator.

A pair of the above two circulation anomalies is clearly identified with the Pacific and Japan (PJ) teleconnection pattern found by Nitta (1987). The development of the anticylonic circulation, which is part of the PJ pattern, reinforces descending motion in the lower troposphere and brings about less cloud cover, resulting in the occurrence of a hot summer, especially in the northern and eastern parts of Japan (e.g., Kurihara and Tsuyuki 1987; Kawamura et al. 1998).

It is crucially important that the PJ pattern excited by convective forcing generates a strong east-west pressure gradient across Japan, because southerly wind anomalies prevail just over central Japan. The persistent PJ pattern affects the development and movement of synoptic-scale disturbances. Actually, a typhoon develops and moves northwestward to the south of Japan under the influence of the enhanced anticyclonic circulation east of Japan, as indicated in Fig. 10. It is quite possible that PJ-related synoptic-scale disturbances give a favorable condition for the frequent appearance of foehn on the coast of the Sea of Japan when the PJ pattern is predominant. We thus anticipate that a combined effect of the excitation of the PJ pattern and associated synoptic-scale disturbances is crucial for the occurrence of the exceptionally prolonged foehn from July 30 to August 3. As for August, the anticyclonic circulation east of Japan becomes weak in association with attenuated convective heating north of the Philippines (not shown).

Figure 12 also shows the observed SST anomaly pattern for July 1999. An important indication is the presence of significantly warm anomalies exceeding $+0.5^{\circ} \mathrm{C}$ over the tropical western North Pacific east of the Philippines. It is very likely that these warm anomalies lead to the enhanced convective activity north of the Philippines, which will be confirmed later using the model. Cool anomalies over the central equatorial Pacific indicate a signature of a La Nina state. Another feature is that very warm anomalies exceeding $+1.5^{\circ} \mathrm{C}$ expand over a wide area east of Japan, which coincides well with the positive $T_{B B}$ anomaly area (Fig. 11). 


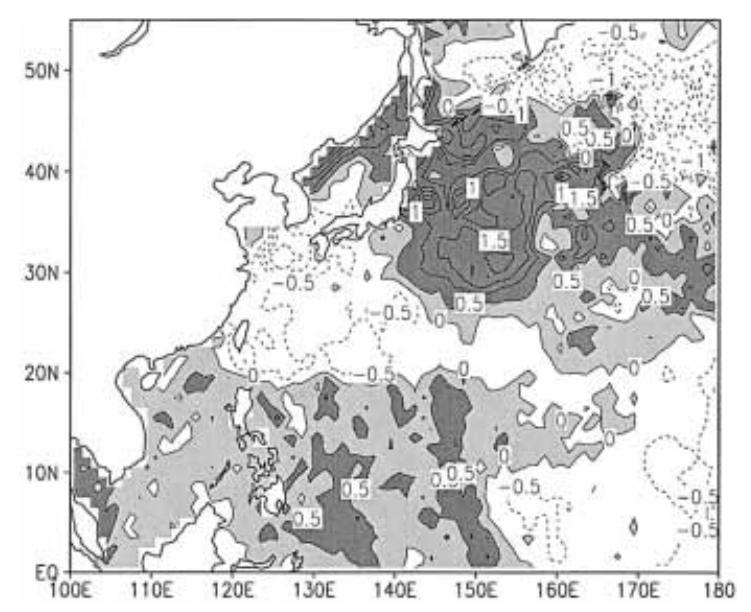

Fig. 12. Observed monthly mean SST anomaly pattern for July 1999. Contour interval is $0.5^{\circ} \mathrm{C}$, and shading denotes regions of positive values.

Kawamura et al. (2001) pointed out that noticeable warm anomalies from the vicinity of Japan to the central North Pacific, appearing when Japan undergoes a severe hot summer, are basically caused by the change in surface heat flux, especially short-wave radiation and latent heat fluxes, relevant to the prominence of an anomalous anticyclonic circulation east of Japan. Their idea can apply to the above feature quite reasonably.

\subsection{AGCM simulation}

Next, we examine the question of whether an AGCM can simulate the basic features of observed low-level circulation anomalies over the western North Pacific and East Asia, especially the vicinity of Japan. If the model is successful in simulating their essential features, the origin of the observed anomalous circulations is attributed to anomalous SST forcing in low latitudes. Figure 13 shows the model-simulated $850-\mathrm{hPa}$ height and wind vector and precipitation anomaly patterns for July 1999. Note that the simulated anomaly fields presented here are derived from the ensemble mean of the three parallel experiments. On the ensemble mean basis, the model simulates increased precipitation in the vicinity of the Philippines, in intimate association with the underlying warm SST anomalies, which indicates a signa-

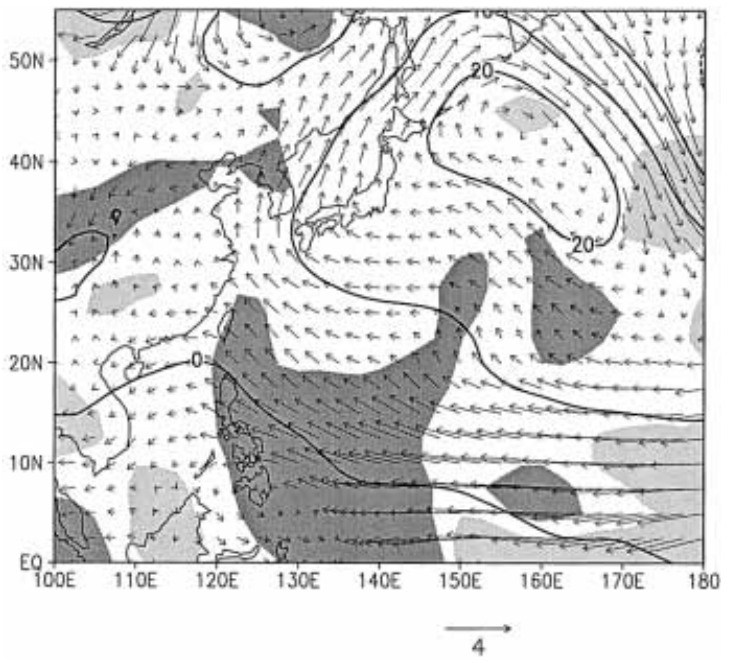

Fig. 13. Model-simulated monthly mean 850-hPa height and wind vector and precipitation anomaly patterns for July 1999, based on the ensemble mean of three parallel simulations. Contour interval is $10 \mathrm{~m}$, and reference arrow is $3 \mathrm{~m} \mathrm{~s}^{-1}$. Heavy and light shadings denote regions greater than $+1 \mathrm{~mm} \mathrm{day}^{-1}$ and less than $-1 \mathrm{~mm}$ day $^{-1}$, respectively.

ture of strong western North Pacific monsoon (Murakami and Matsumoto 1994), but the center of the simulated enhanced convection area shifts to the south compared to that observed (see Fig. 11 again). Another notable feature is establishment of an anticyclonic circulation anomaly east of Japan. Japan is located on the western periphery of this anomalous circulation and covered by southerly wind anomalies, which is similar to the observations. The model, on the contrary, fails to reproduce a significant cyclonic circulation anomaly to the south of Japan, although a weak cyclonic circulation is simulated just over the Philippines. This may result from a systematic error that the model tends to underestimate tropical precipitation over the warm pool region of the western North Pacific (Sugi et al. 1995). Another possible reason is that the AGCM simulation does not incorporate large-scale air-sea feedback processes. For instance, negative SST anomalies south of Japan (Fig. 12) might be interpreted as a result of anomalous surface heat flux and/ 
or wind forcing relevant to convection-induced anomalous circulation. The SST decrease may in turn suppress convection. Yet, we disregard such feedback processes in the model.

Although systematic errors such as local precipitation distribution are indeed present in the model, enhanced southerly wind anomalies along the western periphery of the anomalous circulation centered east of Japan, relevant to the occurrence of the extraordinary prolonged foehn, are basically simulated in terms of anomalous circulation field. This indicates that the anomalous SST forcing is responsible for the establishment and maintenance of the anticyclonic circulation anomaly east of Japan. Since only the three parallel simulations were performed, we cannot fully remove the internal variability of extratropical model atmosphere through the ensemble mean process. Thus, its internal variability may also influence such a circulation anomaly. It is worthwhile to note here that the simulated anticyclonic circulation is accompanied by the underlying warm SST anomalies, as shown in Fig. 12. We think it very unlikely that the in situ warm SST anomalies generate an anomalous anticyclonic circulation in the lower troposphere through local air-sea heat exchanges. As previously stated, it can actually be interpreted that the warm SST anomalies are not the cause, but the result, of a well organized anticyclonic circulation anomaly (Kawamura et al. 2001). We are aware, of course, that local air-sea interactions possibly modify the anomalous anticyclonic circulation.

From the common features between the model-simulated and observed anomalies, it is concluded that the anomalous SST forcing from tropics induces the PJ-like response of extratropical atmosphere over the western North Pacific, resulting in reinforcing southerly geostrophic winds across central Japan through intensification of an east-west pressure gradient. Once large-scale circulation anomalies are initiated and sustained as a result of such an extratropical response, the behavior of associated synoptic-scale disturbances is largely regulated by those anomalies. We emphasize that a combination of the excitation of the PJ pattern and the PJ-related synoptic-scale disturbances can easily provide a favorable condition for the extraordinary persistence of foehn along the coast of the Sea of Japan.

\section{Discussion and concluding remarks}

An important problem remains unsolved. Why is only the 1999 summer exceptional in terms of the occurrence frequency of foehn, as indicated in Fig. 2. Although we pointed out that a combined effect of the dominance of PJ and associated synoptic-scale disturbances favors the extraordinary persistence of foehn, we have given no definitive answers to the above question.

According to Kawamura et al. (1998), the PJ-type response to anomalous convective heating over the Philippine Sea is crucial to the frequent occurrence of extreme summers in East Asia, Japan particularly, in the past two decades. They extracted six typical hot summers (1981, 1984, 1985, 1988, 1989 and 1990) in terms of how large-scale anomalous circulations that cause severe hot summers are strongly regulated by tropical forcing. Based on their classification with respect to the typical hot summer, we thus present, in Fig. 14, the

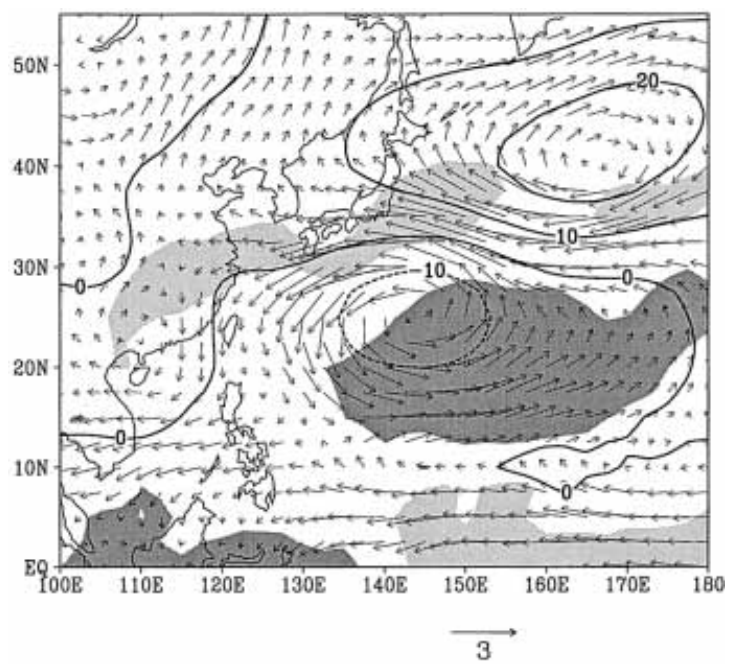

Fig. 14. Composite anomaly patterns of $850-\mathrm{hPa}$ height and wind vector and OLR fields for July in a typical hot summer, based on Kawamura et al's (1998) classification. Contour interval is $10 \mathrm{~m}$, and negative height values are denoted by dashed lines. Heavy and light shadings denote significant negative and positive OLR anomalies, respectively. Reference arrow is $3 \mathrm{~m} \mathrm{~s}^{-1}$. 
composite anomaly map of $850-\mathrm{hPa}$ height and wind vector and outgoing longwave radiation (OLR) fields for July. Comparing this figure with Fig. 11, the most notable difference is the configuration of the PJ pattern. A salient cyclonic circulation anomaly, which is part of PJ, is centered on $25^{\circ} \mathrm{N}, 145^{\circ} \mathrm{E}$, while an anomalous anticyclonic circulation is established to its northeast. A north-south pair of these two vortexes generates easterly wind anomalies between the two. We also see that the anomalous easterly winds expand westward up to Japan. As already shown in Fig. 11, on the other hand, the PJ pattern that appeared in July 1999 is characterized by an east-west pair, rather than a north-south pair of the cells, and the geographical location of its overall pattern is displaced to the west. This clearly results from the westward displacement of an enhanced convection area in the subtropics. The center of negative $T_{B B}$ anomaly area (Fig. 11 ) is shifted about $20^{\circ}$ westward and $2-3^{\circ}$ northward, compared to that of the corresponding negative OLR anomalies. Thus, it can be interpreted that the westward displacement of intense convection area changes the geographical location and configuration of $\mathrm{PJ}$, eventually leading to the intensification of a strong east-west pressure gradient across Japan.

Another question may be raised: why did the westward displacement of enhanced convection area occur in July 1999? The most likely cause is the extraordinary feature of SST anomalies over the warm pool region of the western North Pacific. Looking at Fig. 15, which shows the composite July SST anomaly map for the typical hot summer, it turns out that significant warm SST anomalies at low latitudes are indicated over the warm pool region around $140^{\circ}-160^{\circ} \mathrm{E}$. It should be noted, however, that warm anomalies observed in July 1999 are pronounced to the west of about $150^{\circ} \mathrm{E}$ (see Fig. 12 again). We anticipate that the westward shift of the warm anomalies over the tropical western North Pacific brings about a similar shift of the enhanced tropical convection in that vicinity.

Major findings of this study are summarized as follows. The occurrence of extreme foehns observed at Toyama in the Hokuriku district reaches 7 days in midsummer of 1999, which is the largest number of the foehn days during the

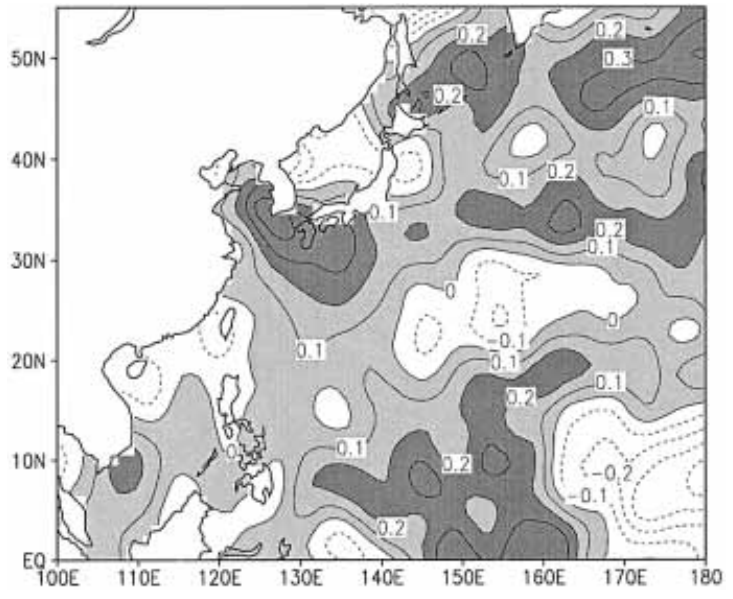

Fig. 15. As in Fig. 14 but for SST anomalies. Contour interval is $0.1^{\circ} \mathrm{C}$, and shading denotes regions of positive values.

25-year period 1975-1999, using four objective criteria characteristic of foehns. A sequence of 5 foehn days from July 30 to August 3 makes the 1999 summer quite exceptional. The extraordinary prolonged foehn prevails, not only at the Toyama Plain, but also along the coast of the Sea of Japan of central Japan, and associated local wind patterns show that there is a remarkable difference between the early and later periods of the foehn sequence of 5 days. At the early period (July 30-August 1), the pressure gradient becomes pronounced between a rapidly developing extratropical cyclone over southeastern Siberia and an intensified anticyclone east of Japan, whereas at the later period (August 2-3), a combination of the same anticyclone and a typhoon migrating northward along its western periphery induces a new strong east-west pressure gradient around Japan. These synoptic-scale conditions, which lead to definite intensification of southerly geostrophic winds over central Japan, provide a favorable condition for the extraordinary persistence of foehn.

We also find from the simulation and observation that on a monthly mean basis, a noticeable east-west pressure gradient across Japan is induced due to the predominance of PJ in response to tropical convective heating, and the persistent PJ pattern influences the develop- 
ment and movement of adjacent synoptic-scale disturbances, such as a growing typhoon and an enhanced anticyclonic circulation east of Japan seen at both periods. We anticipate that a combined effect of the excitation of the PJ pattern and associated synoptic-scale disturbances is crucial for the occurrence of exceptionally prolonged foehn. The PJ pattern that appeared in July 1999 is unusual in terms of its geographical location and configuration. This is attributed to the westward displacement of an enhanced convection area over the warm pool region of the western North Pacific; that is, that area is shifted about $20^{\circ}$ westward and $2-3^{\circ}$ northward, compared to the typical hot summer that Japan underwent. It is presumed that the westward shift of marked warm SST anomalies over the warm pool region leads to a similar shift of the intensified convection in that vicinity.

Japan, its northern and eastern parts particularly, again experienced a severe hot summer in 2000. Localization and enhancement of tropical convection are observed in July over the warm pool region of the western North Pacific as well as July 1999. It seems that both summers exhibit very similar anomalous states of the tropical western Pacific atmosphere-ocean system. Associated with this, we also see the frequent occurrence of foehn in the Hokuriku district in the midsummer of 2000. Further analysis should also be made with respect to the case of 2000 .

\section{Acknowledgments}

Comments by two anonymous reviewers were extremely helpful. This research was supported by the Japan Science and Technology Agency, through the project study of disaster predictions in global hydrologic processes; by Grants-in-Aids (11640430) of the Japanese Ministry of Education, Science, Sports and Culture; and by the Mitsubishi Foundation for the Promotion of Science.

\section{References}

Arakawa, S., 1988: An introductory survey of local circulation. Note on Meteorological Research, 163, 1-22, in Japanese.

Gill, A.E., 1980: Some simple solutions for heatinduced tropical circulation. Quart. J. Roy. Meteor. Soc., 106, 447-462.
Ikawa, M. and Y. Nagasawa, 1989: A numerical study of a dynamically induced foehn observed in the Abashiri-Ohmu area. J. Meteor. Soc. Japan, 67, 429-458.

JMA, 1993: Outline of operational numerical weather prediction at Japan Meteorological Agency. NPD/JMA, 128pp.

Kalnay, E., M. Kanamitsu, R. Kistler, W. Collins, D. Deaven, L. Gandin, M. Iredell, S. Saha, G. White, J. Woollen, Y. Zhu, M. Chelliah, W. Ebisuzaki, W. Higgins, J. Janowiak, K.C. Mo, C. Ropelewski, J. Wang, A. Leetmaa, R. Reynolds, Roy Jenne and Dennis Joseph, 1996: The NCEP/NCAR 40-year reanalysis project. Bull. Amer. Meteor. Soc., 77, 437-471.

Kawamura, R., M. Sugi, T. Kayahara and N. Sato, 1998: Recent extraordinary cool and hot summers in East Asia simulated by an ensemble climate experiment. J. Meteor. Soc. Japan, 76, 597-617.

, T. Matsuura and S. Iizuka, 2001: Interannual atmosphere-ocean variations in the tropical western North Pacific relevant to the Asian summer monsoon-ENSO coupling. $J$. Meteor. Soc. Japan, 79, 883-898.

Kurihara, K. and T. Tsuyuki, 1987: Development of the barotropic high around Japan and its association with Rossby wave-like propagations over the North Pacific: analysis of August 1984. J. Meteor. Soc. Japan, 65, 237-246.

Matsuno, T., 1966: Quasi-geostrophic motions in the equatorial area. J. Meteor. Soc. Japan, 44, 2543.

Murakami, T. and J. Matsumoto, 1994: Summer monsoon over the Asian continent and the western North Pacific. J. Meteor. Soc. Japan, 72, 719-745.

Nitta, T., 1987: Convective activities in the tropical western Pacific and their impact on the Northern Hemisphere summer circulation. J. Meteor. Soc. Japan, 65, 373-390.

Parker, D.E., C.K. Folland and M. Jackson, 1995: Marine surface temperature: Observed variations and data requirements. Clim. Change, 31, 559-600.

Saito, K. and M. Ikawa, 1991: A numerical study of the local downslope wind "Yamaji-kaze" in Japan. J. Meteor. Soc. Japan, 69, 31-56. -, 1993: A numerical study of the local downslope wind "Yamaji-kaze" in Japan. Part 2: Non-linear aspect of the 3-D flow over a mountain range with a col. J. Meteor. Soc. Japan, $\mathbf{7 1}, 247-272$.

Scorer, R.S. and H. Klieforth, 1959: Theory of mountain waves of large amplitude. Quart. J. Roy. Meteor. Soc., 85, 131-143. 
Sugi, M., K. Kuma, K. Tada, K. Tamiya, N. Hasegawa, T. Iwasaki, S. Yamada and T. Kitade, 1990: Description and performance of the JMA operational global spectral model (JMAGSM89). Geophys. Mag., 43, 105-130.

Sugi, M., R. Kawamura and N. Sato (1995): The cli- mate simulated by the JMA global model. Part I: Global feature. Report of the National Research Institute for Earth Science and Disaster Prevention, 54, 155-180.

Yoshino, M., 1976: Local wind bora. University of Tokyo Press, 289pp. 